\title{
Designing an Advanced Electrical Motor for Propulsion of Electric Aircraft
}

\author{
Dmitry Golovanov ${ }^{1}$, David Gerada ${ }^{2}, Z_{\text {Zeyuan } \mathrm{Xu}^{3} \text {, and Chris Gerada }}^{4}$ \\ PEMC Group, University of Nottingham, Nottingham, NG72RD, UK \\ Andrew Page ${ }^{5}$, and Tadashi Sawata ${ }^{6}$ \\ Electronic Controls and Motor Systems, Collins Aerospace, Solihull, B90 4SS, UK
}

\begin{abstract}
A prototype motor rated for $500 \mathrm{~kW} \mathrm{3,000} \mathrm{rpm} \mathrm{has} \mathrm{been} \mathrm{developed} \mathrm{for} \mathrm{aircraft} \mathrm{electric}$ propulsion. The design of the motor was optimized using a coupled parameter problem of electromagnetic, mechanical and thermal performances. A high power density of over $5 \mathrm{~kW} / \mathrm{kg}$ is demonstrated without resorting to intensive direct liquid cooling. The design process considered variables including the winding conductor type, pole/slot combination, dimensions, winding layout and power electronics requirements. The final chosen design is a 3 $\times 3$-phase 30-pole 36-slot surface permanent magnet motor with Cobalt-Iron laminations, $\mathrm{Sm}_{2} \mathrm{Co}_{17}$ Halbach array magnets and litz wire for an optimum performance.
\end{abstract}

\section{Introduction}

In recent years, technologies for electric propulsion systems including pure electric and hybrid electric variants have gained increasing attentions. The optimization of power density of propulsion motors is one of the key drivers of the technology, where a coupled problem of electromagnetic and thermal designs need to be considered simultaneously. Water glycol has been commonly used for cooling of power electronic systems on aircraft and it would be desirable if the existing cooling medium can also be used for propulsion motors. This paper details the work undertaken in arriving at the design of a $500 \mathrm{~kW} \mathrm{3,000} \mathrm{rpm} \mathrm{propulsion} \mathrm{motor} \mathrm{which} \mathrm{is} \mathrm{optimized} \mathrm{for} \mathrm{indirect} \mathrm{cooling}$ by water glycol. It describes the requirements, the steps taken to identify the optimum winding type as well as the optimum slot-pole combination. For the chosen slot-pole combination more detailed calculations are then performed, including the rotor losses, as well as losses within the non-active parts. Finally aspects related to the thermal management and the mechanical design are described.

\section{Propulsion Motor Requirements}

The requirements for the $500 \mathrm{~kW}$ propulsion motor are summarized in the Table 1 . The key requirement is to meet the performance values listed in the table, while maximizing the machine power density (ratio of power to total mass) and efficiency. Typically the highest power density electrical machines feature direct cooling, for example oil-spray or oil-jet, however in this work an oil-free solution is developed, with water cooling and a dry-winding configuration being used instead.

Table 1 - Main requirements for $500 \mathrm{~kW}$ propulsion motor

\begin{tabular}{|l|l|}
\hline Requirement & Comment \\
\hline Power $=500 \mathrm{~kW}$ & Continuous power rating $-500 \mathrm{~kW}$ \\
\hline Speed $=3,000 \mathrm{rpm}$ & Propeller speed \\
\hline DC Bus $=600 \mathrm{~V}$ & Minimum $480 \mathrm{~V}$ DC \\
\hline Liquid Cooling & Water-cooled, non-direct cooling (dry-winding), $50^{\circ} \mathrm{C}$ water inlet temperature \\
\hline
\end{tabular}

\footnotetext{
${ }^{1}$ Research Fellow, PEMC Group, University of Nottingham, UK

2 Senior Research Fellow, PEMC Group, University of Nottingham, UK

${ }^{3}$ Senior Research Fellow, PEMC Group, University of Nottingham, UK

${ }^{4}$ Professor of Electrical Machines, PEMC Group, University of Nottingham, UK

${ }^{5}$ Principal Engineer, Electronic Controls and Motor Systems, Collins Aerospace, UK

${ }^{6}$ Senior Engineering Consultant, Electronic Controls and Motor Systems, Collins Aerospace, UK
} 


\section{Tradeoff Studies}

It has been shown that the Permanent Magnet Synchronous Machines (PMSM) with internal rotor (IR) topology and Halbach permanent magnet (PM) array allow for reaching the highest power density values in the target power range of this project [1]. Thereby, this type of the machine was selected for further consideration within this work.

At the initial stage of design two types of winding configurations are considered: concentrated winding $(\mathrm{CW})$ and distributed winding (DW). For each type of winding configuration the optimization of machine geometry is performed for a wide range of pole pairs and pole/slot combinations [2]. The machine is water cooled with an inlet coolant temperature of $50^{\circ} \mathrm{C}$. Best in class Cobalt-Iron alloy is selected for the stator core [3]. High energy density $\mathrm{Sm}_{2} \mathrm{Co}_{17}$ permanent magnets are considered for the rotor [4] - [5].

The optimization model that was used for preliminary design is based on analytical approach. Parametric analytical models are built for the electromagnetic sizing and analysis, thermal analysis, and mechanical analysis [1], as shown in Fig. 1, with the aforesaid three domains linked so that any design change can be instantly evaluated from the electromagnetic/thermal/mechanical aspects. A Single Objective Genetic Algorithm (SOGA), is used with the parametric models with the single optimization goal of maximizing the power to mass ratio $(\mathrm{kW} / \mathrm{kg})$

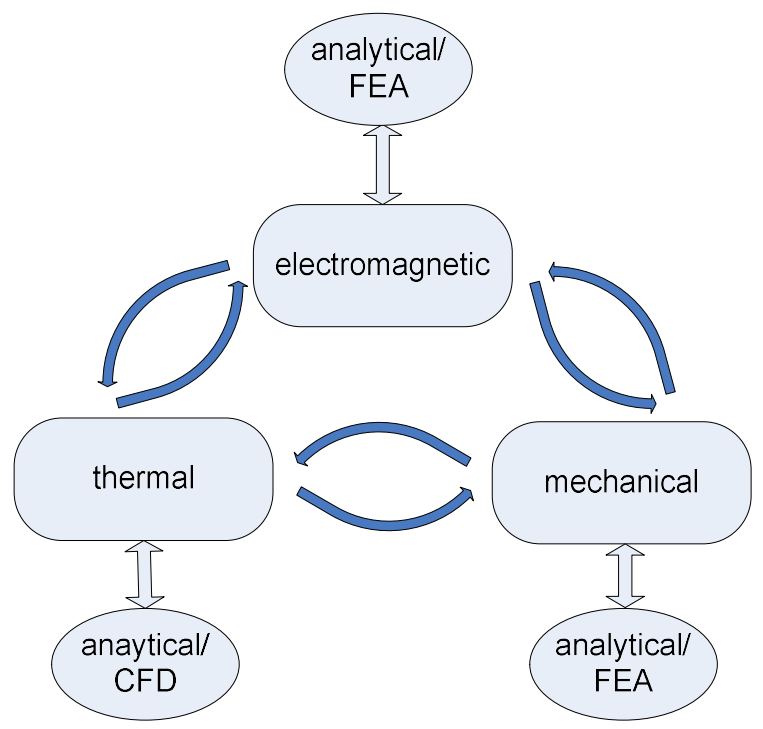

Fig. 1 Multidomain analysis approach used for the maximizing the machine power density

\section{A. Distributed Winding}

For the distributed winding configuration, 1 and 2 slots per pole per phase designs are investigated. In order for the design to be considered as feasible, the constraints presented in Table 2 are defined. Basically the power factor has to be over 0.75 based on the available converter VA, and the winding temperature is limited to up to $200^{\circ} \mathrm{C}$ based on the selected material insulation class.

Table 2 List of constraints

\begin{tabular}{|l|l|}
\hline \multicolumn{1}{|c|}{ Limit } & \\
\hline$>0.75$ & Power factor \\
\hline$>0.95$ & Efficiency \\
\hline$<2.1 \mathrm{~T}$ & Tooth flux density under load condition \\
\hline$<2.1 \mathrm{~T}$ & Core flux density under load condition \\
\hline$<200^{\circ} \mathrm{C}$ & Maximum temperature of the end-windings \\
\hline$<200^{\circ} \mathrm{C}$ & Maximum temperature of the coil inside the slot \\
\hline
\end{tabular}






a)

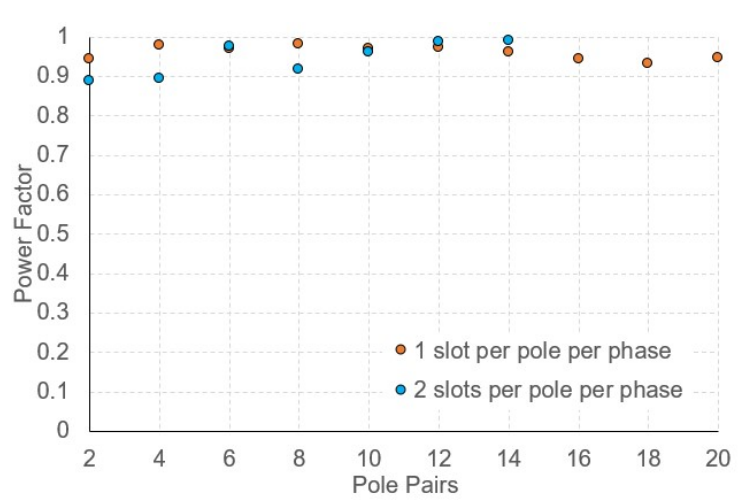

b)

Fig. 2 Results of $500 \mathrm{~kW}$ motor optimization for distrebuted winding configuration; a) power density; b) power factor

The results of optimization are given in Fig. 2. It can be seen that the maximum value of power density $5.5 \mathrm{~kW} / \mathrm{kg}$ for 1 slot per pole per phase configuration can be achieved at 16 pole pairs $(f=800 \mathrm{~Hz})$. For 2 slots per pole per phase machine the maximum power density is $4.3 \mathrm{~kW} / \mathrm{kg}$ at 10 pole pairs $(f=500 \mathrm{~Hz})$. Fig. $2 \mathrm{~b}$ shows the power factor values which are $>0.9$ for almost all optimized designs, due to the low inductance of DW-PMSM. This means that although the power factor is a constraint, it is not really affecting the resulting geometry with the thermal constraint being the main limiting factor in this case.

\section{B. Concentrated Winding}

Concentrated-wound machines require the careful selection of slot-pole combination, as this is very sensitive on the winding factor, presence of sub-harmonics and hence $\mathrm{AC}$ winding and magnet losses. The most suitable slot-pole combinations for a $3 \times 3$ phase system and related winding coefficients are highlighted in green in Table 3.

Table 3 Pole pairs - Slots combinations for PMSM with concentrated winding

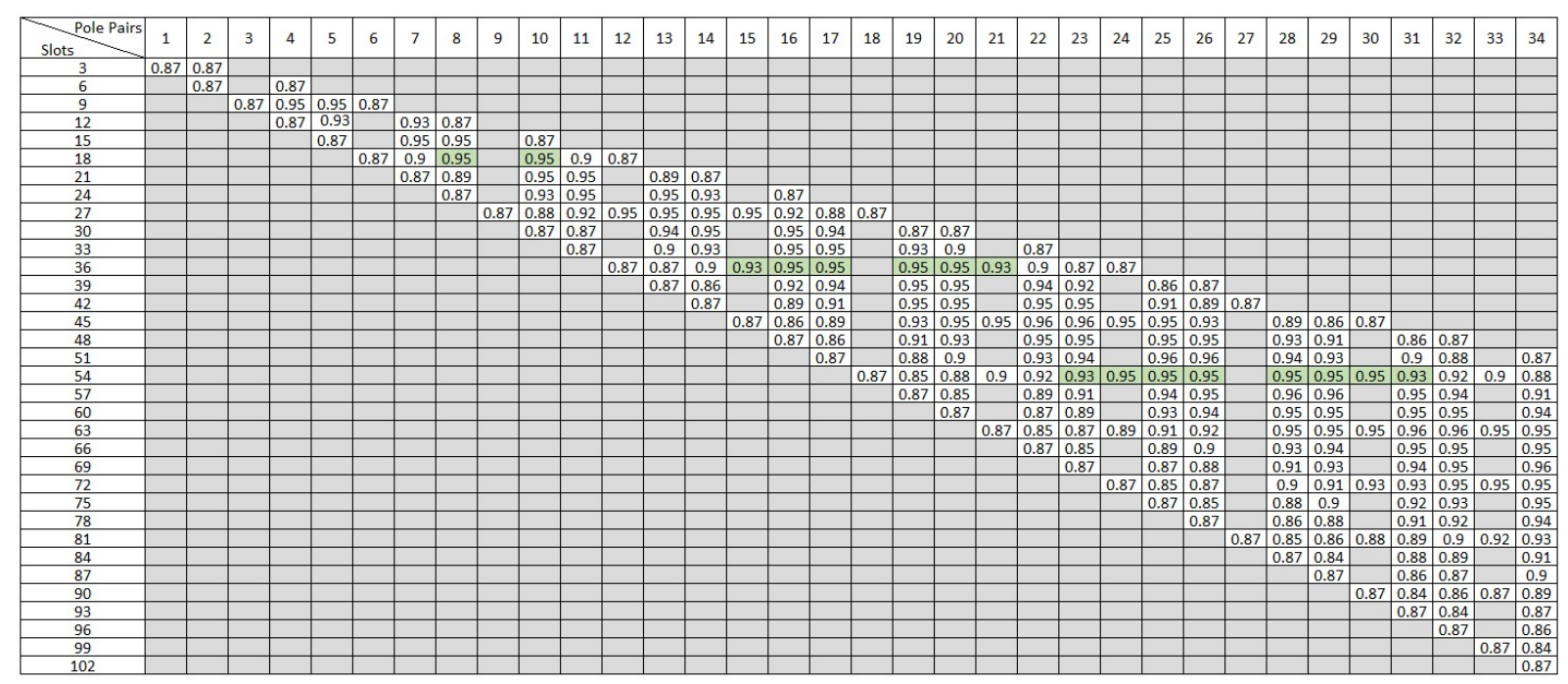

The procedure of optimization is similar to the one described earlier for the DW configuration. The power density and power factor distributions for the machine designs with pole/slots combinations presented in Table 3 are given in Fig. 3. For the pole-pair number greater than 15 the power density remains broadly in the range from $4.3 \mathrm{~kW} / \mathrm{kg}$ to $4.5 \mathrm{~kW} / \mathrm{kg}$ and subsequently reduces for higher pole pair numbers $(>28)$. The values of power factor are in the range from 0.77 to 0.89 , markedly lower than those for the distributed-wound machines due to the inherently higher inductance for machines employing concentrated windings, hence the power-factor constraint in this case bears a stronger influence on the machine geometry and the results of the optimization. 

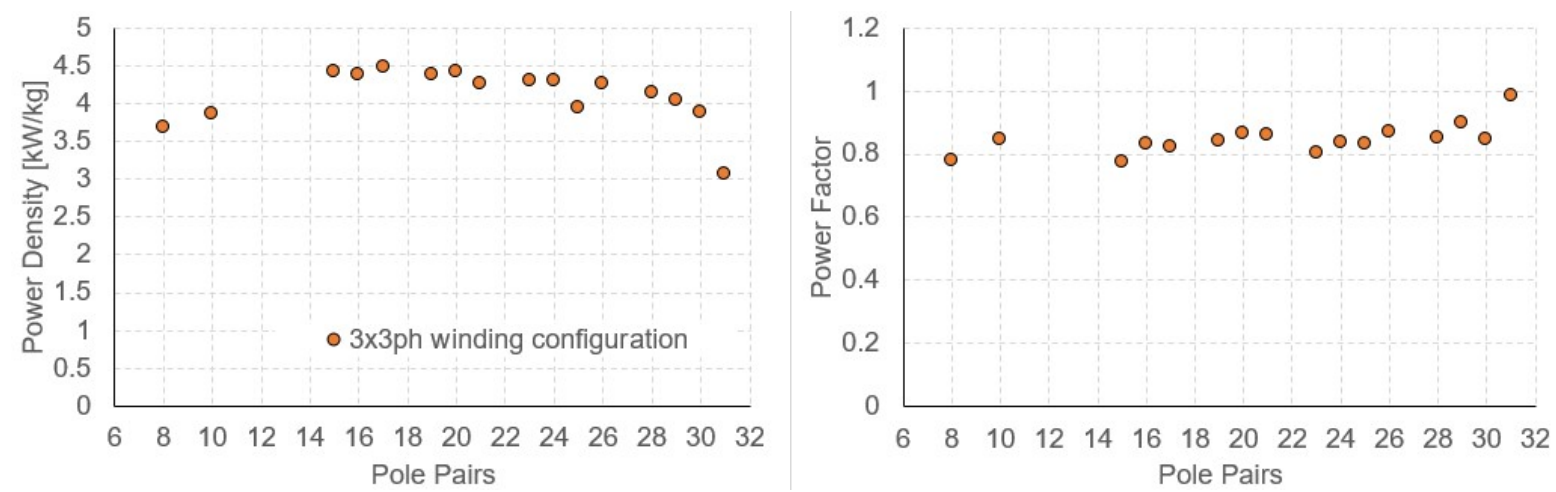

Fig. 3 Results of $500 \mathrm{~kW}$ motor optimization for concentrated winding configuration

Despite the fact from the foregoing analysis that DW machines exhibit higher nominal power density with respect to the CW-designs, concentrated windings are chosen for further investigation since for the restricted volumetric constraints the CW featured easier assembly and cooling. The basic parameters of the selected motor are shown in Table 4. The motor parameters are given for two types of shaft material: Steel and Titanium. The use of titanium as shaft material significantly reduces the shaft mass from $29.6 \mathrm{~kg}$ to $17 \mathrm{~kg}$. Thereby the power density of the machine can be increased from $4.3 \mathrm{~kW} / \mathrm{kg}$ (as presented in Fig. 3) to $4.8 \mathrm{~kW} / \mathrm{kg}$.

Table 4 Parameters of $500 \mathrm{~kW}$ motor with concentrated winding based on preliminary analytical design and analysis

\begin{tabular}{|l|c|c|}
\hline \multicolumn{1}{|c|}{ Parameter } & Steel shaft & Ti - shaft \\
\hline Pole pairs & 15 & 15 \\
\hline Slots & 36 & 36 \\
\hline Power Factor & 0.83 & 0.82 \\
\hline Active Mass [kg] & & \\
\hline Passive Mass [kg] & 61.7 & 49.1 \\
\hline Efficiency & 0.97 & 0.97 \\
\hline Total Mass [kg] & 116 & 103.4 \\
\hline Power Density [kW/kg] & 4.3 & 4.8 \\
\hline Maximum Coil Temperature $\left[{ }^{\circ} \mathrm{C}\right]$ & 199 & 203 \\
\hline
\end{tabular}

\section{Finite Element Optimization}

After completing the preliminary electromagnetic design based on analytical formulation, as described in the preceding sections, finite element (FE) optimization was performed to further refine the selected slot-pole combination. The used optimization technique is the same as was described above, with the only difference being that the analytical formulation is replaced with the FE analysis. The FE optimization was performed for the machine with following parameters: concentrated winding, 30 poles, 36 slots, Ti- shaft, Cobalt-Iron as stator material, $\mathrm{Sm}_{2} \mathrm{Co}_{17}$ as PM material.

The feasible designs with a Pareto front are shown in Fig. 4 in a form of Power Density - Current Density correlation. In total 3,394 designs were estimated and 1,272 feasible designs were obtained. 


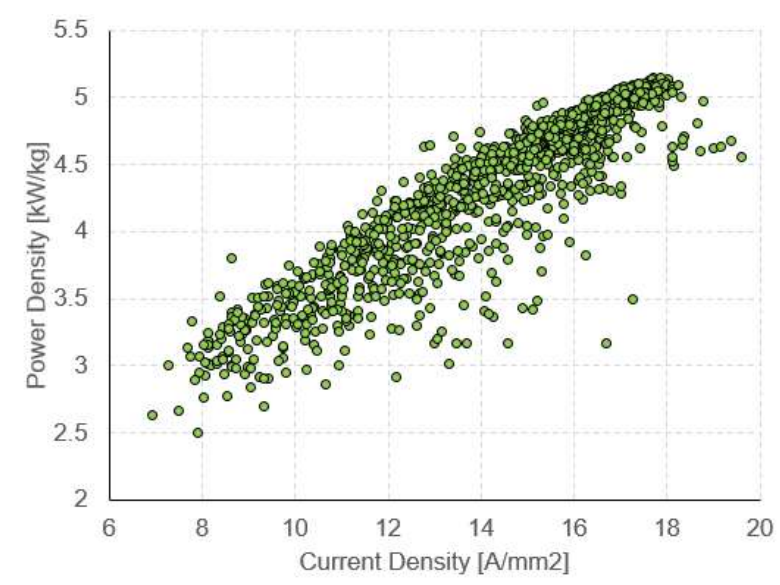

Fig. 4 Results of FE optimization - Pareto front

The main parameters of the selected machine after FE optimization are summarized in Table 5.

Table 5 Parameters of the selected machine after FE optimization

\begin{tabular}{|l|c|}
\hline \multicolumn{1}{|c|}{ Parameter } & Value \\
\hline Phase current Iph [A] & 369 \\
\hline Phase voltage Vph [V] & 208 \\
\hline EMF [V] & 159 \\
\hline Fundamental frequency [Hz] & 750 \\
\hline Power Factor & 0.73 \\
\hline Efficiency & 0.97 \\
\hline Power density $[\mathrm{kW} / \mathrm{kg}]$ & Approximately 5.0 \\
\hline
\end{tabular}

The three 3-phase systems are arranged as shown in Fig. 5a. The alternative configuration that also can be realized is presented in Fig. 5b. The advantage of the chosen winding arrangement is that it requires less length for coil connection. On the other hand this system might be mechanically unbalanced in case of powering from one converter or in case of unbalance between the converters.

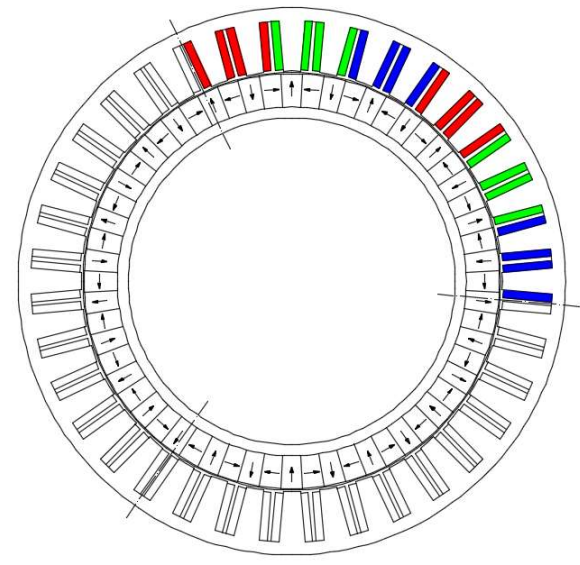

a)

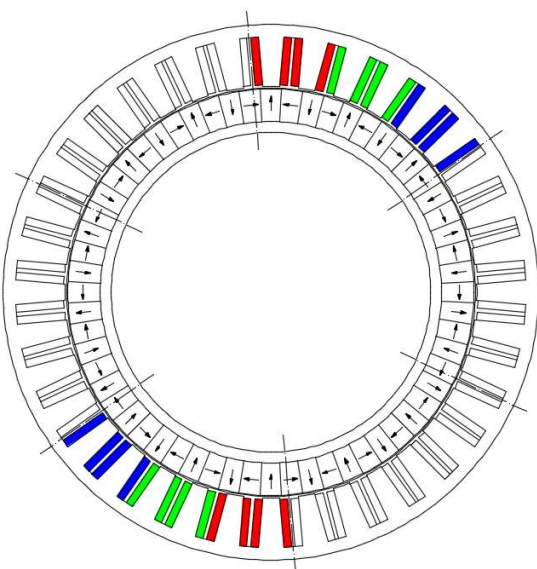

b)

Fig. 5 Arrangement of 3-phase winding systems

\section{Wire Selection}

The selection of type of wire was based on the results of AC copper losses generated at the nominal operating condition $-3,000 \mathrm{rpm}$ and power $500 \mathrm{~kW}$. Since the fundamental frequency of the motor is $750 \mathrm{~Hz}$ the skin and proximity have a large impact on the copper losses. Within the project, two types of wire were considered: litz wire as shown in Fig 6 and standard round wire. 


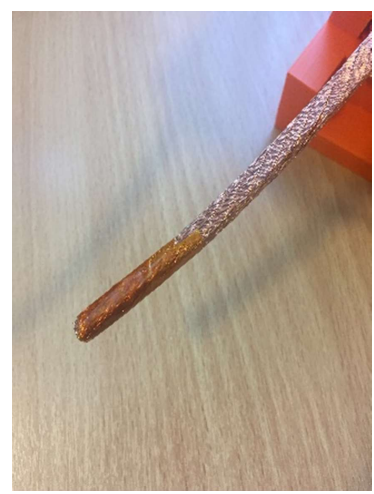

Fig 6 Litz wire

\section{A. Round wire}

The estimation of AC to DC copper loss ratio was performed by FE analysis (FEA). One phase of the machine was simulated at the strand level, as shown in Fig. 7. The diameter of round wire was considered to be equal to $1 \mathrm{~mm}$. The round conductors are uniformly arranged within a bundle as shown in Fig. 7. Due to the flux leakage in the slot that leads to significant current circulation between parallel strands, an uneven distribution of current density across the bundle can be observed - Fig. 7. The resulting AC/DC ohmic loss ratio is relatively high, being 4.64.

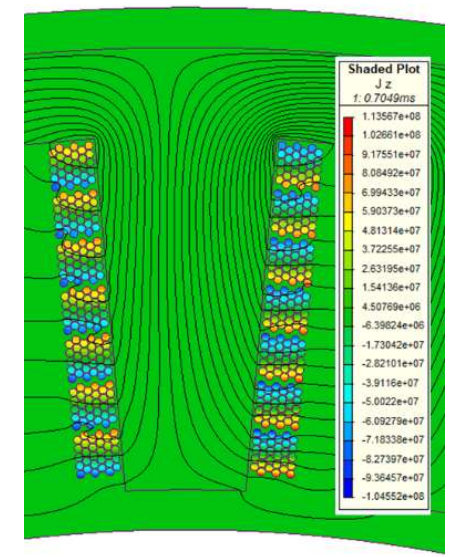

Fig. 7 Current density distribution across the bundle of round wire

\section{B. Litz wire}

The strand transposition within litz wire prevents circulating current between parallel strands. Skin and proximity effects become the main source of AC loss. These effects can be suppressed by selecting an appropriate strand diameter. The AC loss modelling for litz wire was performed by FEA. For the purpose of comparison with a standard round wire, a first simulation was done for $1 \mathrm{~mm}$ strand diameter. Thirty strands of $1 \mathrm{~mm}$ diameter can be accommodated in a bundle assuming that the litz wire fill factor is 0.6 . As can be seen from Fig. 8 the current density is evenly distributed among the strands in litz wire. The AC to DC loss ratio is 1.16 due to the proximity and skin effects. 


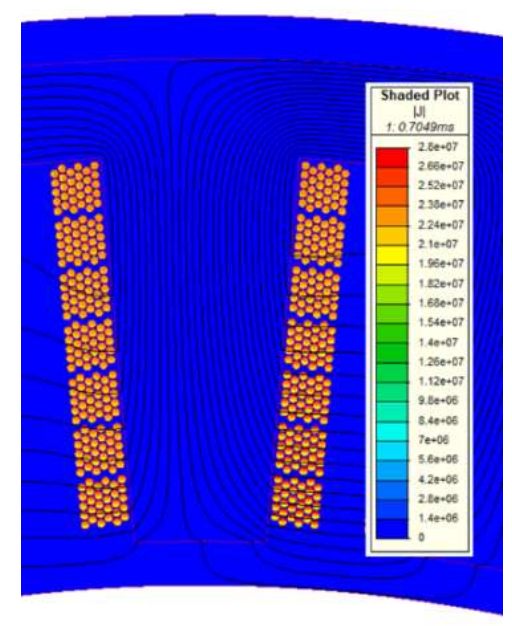

Fig. 8 Current density distribution litz wire with a strand diameter $1 \mathrm{~mm}$

Another simulation was performed for $0.4 \mathrm{~mm}$ strand diameter, as shown in Fig 9. In this case, 192 strands of $0.4 \mathrm{~mm}$ diameter can be accommodated the bundle. The estimated AC/DC ratio is further reduced down to 1.04.

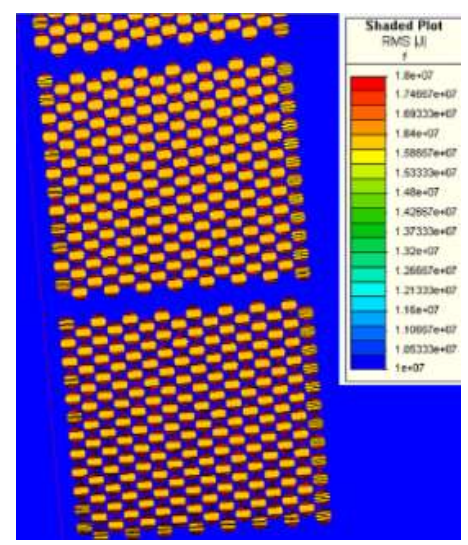

Fig 9 Current density distribution within litz wire with a strand diameter $0.4 \mathrm{~mm}$

The comparison of AC loss among the considered wires shows that employing litz wire is advantageous. Therefore it has been selected for machine prototyping.

\section{VI.Finalization of Electromagnetic design of the machine}

\section{A. Stator Material Lamination Thickness Selection}

Cobalt-Iron alloy $(48 \% \mathrm{Co})$ was selected as stator material since it has favorable magnetization properties among the best in class electromagnetic steels. The saturation point of Cobalt-Iron alloy is around $2.3 \mathrm{~T}$ which is markedly higher in comparison with that of silicon steels.

The iron loss comparison for $0.055 \mathrm{~mm}, 0.1 \mathrm{~mm}$ and $0.2 \mathrm{~mm}$ lamination thickness in Cobalt-Iron is given in Fig. 10 . Due to the high fundamental frequency the iron losses for $0.2 \mathrm{~mm}$ lamination thickness are significantly higher than for $0.055 \mathrm{~mm}$ and $0.1 \mathrm{~mm}$ laminations. The iron loss is $1.9 \mathrm{~kW}$ for $0.055 \mathrm{~mm}$ lamination thickness while for $0.1 \mathrm{~mm}$ thickness it is just over $2.1 \mathrm{~kW}$. For machine prototyping Cobalt-Iron with a thickness of $0.055 \mathrm{~mm}$ was selected. 


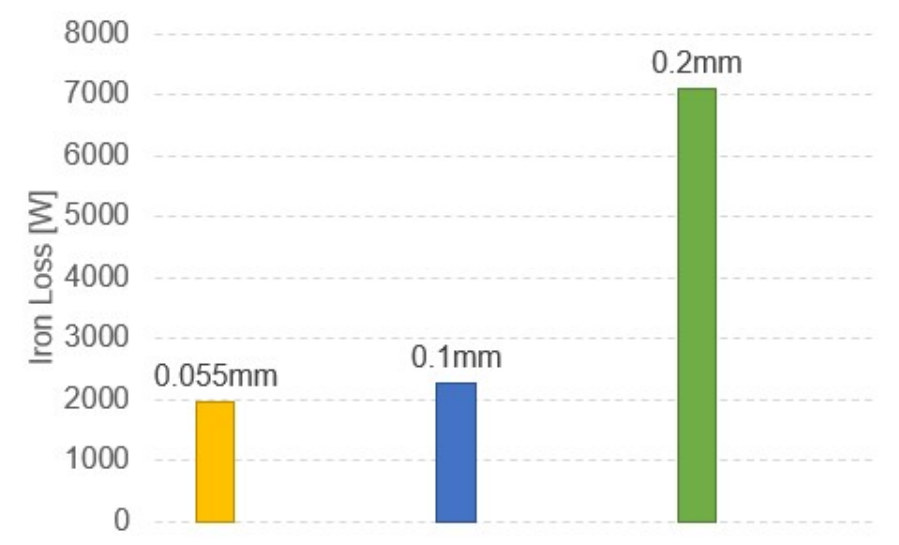

Fig. 10 Iron loss comparison for different thickness of Cobalt-Iron

\section{B. Rotor design}

From the electromagnetic point of view the rotor design contains Halbach PM array with high grade $\mathrm{Sm}_{2} \mathrm{Co}_{17}$ permanent magnets, carbon fiber sleeve and a titanium rotor core. Each pole of Halbach array includes one radially magnetized PM, and two tangentially magnetized PMs. The PMs have sectored shape, as shown in Fig. 11.



Fig. 11 Rotor design

Shows the rotor design.

The estimation of electromagnetic power for the machine with the aforementioned rotor design has been done for the rotor temperature of $150^{\circ} \mathrm{C}$, as shown in Fig. 12.

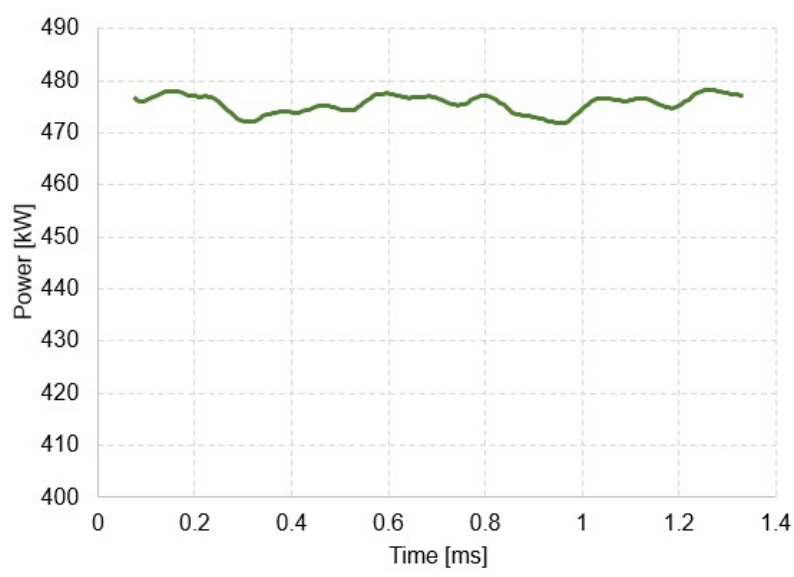

Fig. 12 Electromagnetic power

\section{Analysis of eddy-current loss in permanent magnets}

The high fundamental electrical frequency leads to additional eddy-current losses on the surface of PM. The most effective way of suppressing of such type of losses is permanent magnet segmentation along the axial direction. At 
the preliminary stage of design the 3D FEM was performed for different segment length: $0.7 \mathrm{~mm}, 2.5 \mathrm{~mm}, 10 \mathrm{~mm}$. The results of eddy-current loss evaluation were summarized and presented in Fig. 13, Fig. 14. There is non-linear correlation between PM segment length and eddy-current losses. For $0.7 \mathrm{~mm}$ segment length the eddy-current loss is only $70 \mathrm{~W}$ in comparison with $680 \mathrm{~W}$ and $4,600 \mathrm{~W}$ for $2.5 \mathrm{~mm}$ and $10 \mathrm{~mm}$ PM segment length respectively.

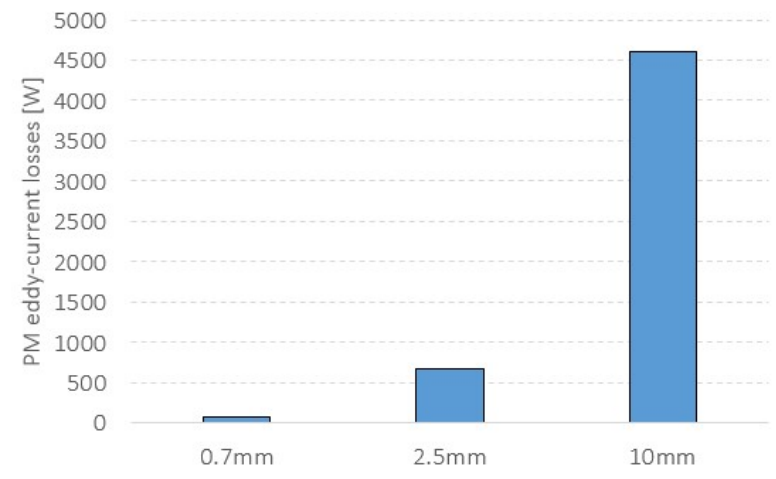

Fig. 13 PM eddy-current loss comparison for different segmentation

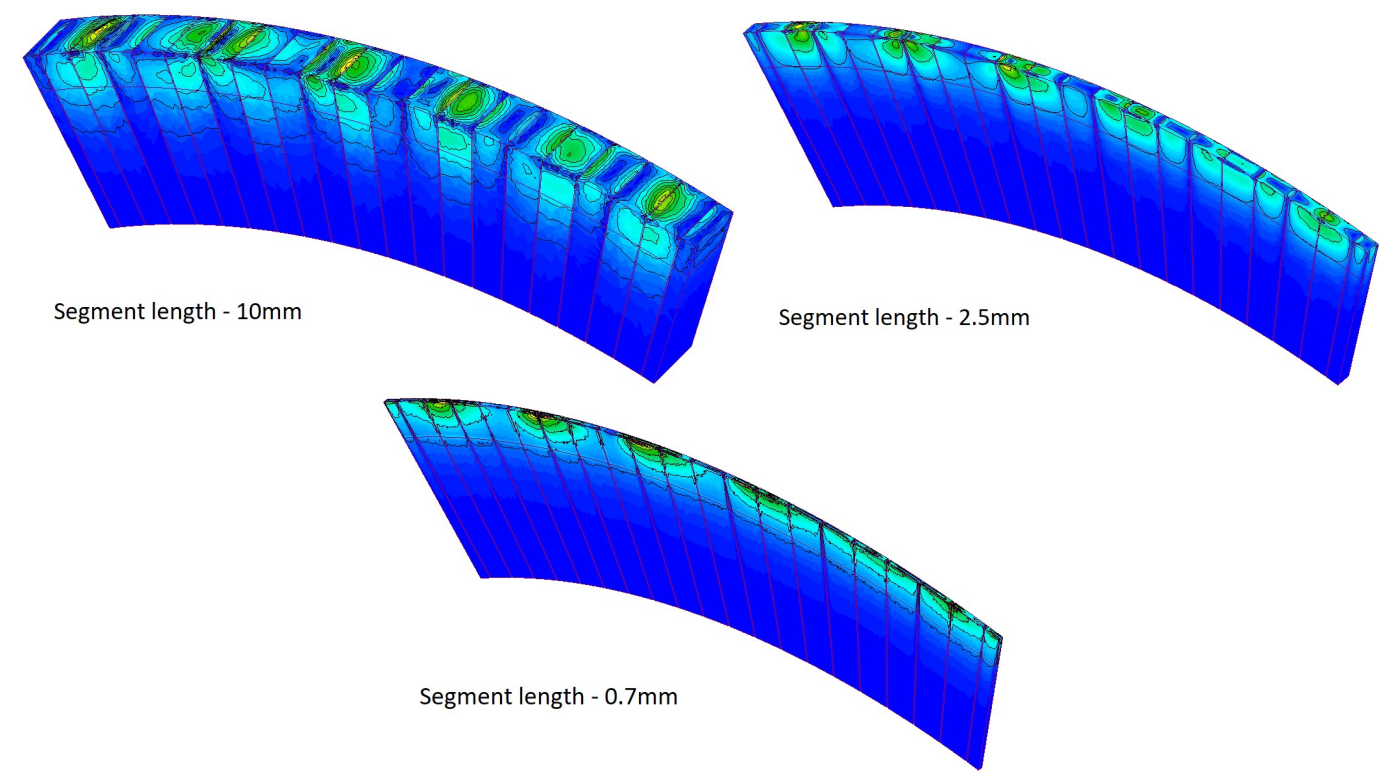

Fig. 14 Eddy-current distribution inside PMs

The permanent magnet eddy-current modelling for the final design with $1 \mathrm{~mm}$ segmentation is presented in Fig. 15 . The simulation was performed for sinusoidal and PWM current waveform. For the sinusoidal excitation the PM loss $\sim 181 \mathrm{~W}$ while for PWM waveform it is reaching $286 \mathrm{~W}$.

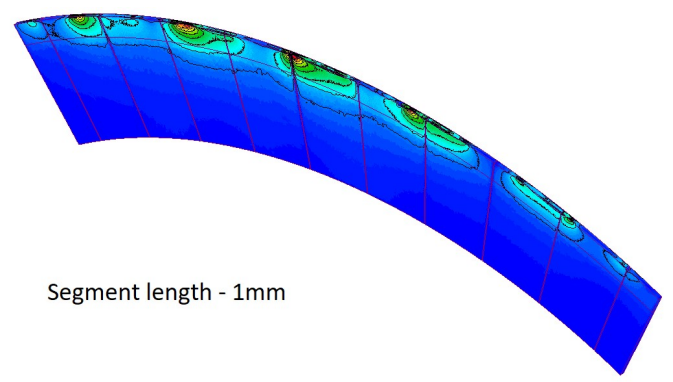

Fig. 15 PM eddy-current analysis for a final design with PWM waveform 


\section{Mechanical Design of the Machine}

The machine mechanical structure follows the overall optimization which seeks to minimize the total machine mass. The overall dimensions of the machine are about $170 \mathrm{~mm}$ length with a diameter of $550 \mathrm{~mm}$. With the power receptacles attached to the rear of the machine and coolant inlet/outlet ports, the dimensions of the envelope are about $\varnothing 570 \mathrm{~mm} \times 290 \mathrm{~mm}$, as shown in Fig. 16. The exploded view of machine is shown in Fig. 14. The machine housing is integrated with a water jacket to remove heat from the stator core, heat can also be removed from two ends of coils by advanced cooling methods. Permanent magnets are attached to the rotor disk surface with a carbon sleeve to retain the magnets at the rotor surface at a maximum speed of 3,000 rpm. The carbon sleeve is pre-stressed to avoid any tensile stress within the magnets under centrifugal force at maximum rotating speed. Two bearing sets mounted at the front and rear flanges connect the rotor and stator of the machine together. Power connectors are attached to the rear flange of the machine.

Fig. 16 Machine overview and envelope

\section{Fig. 17 Machine exploded view}

The active and passive mass distribution of the machine is shown in Fig. 18, with around $40 \%$ being passive mass while the remaining $60 \%$ being active mass. The overall power density of the machine is approximately $5 \mathrm{~kW} / \mathrm{kg}$. It should be mentioned that the passive mass of the machine which consists of machine housing water jacket, two end flanges, rotor shaft, rotor hub and bearing sets, is a subject for further improvements and optimization. 


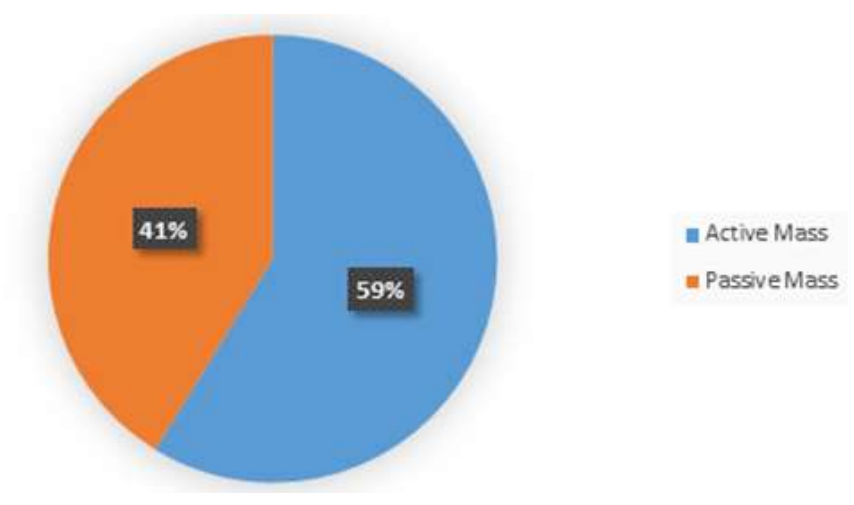

Fig. 18 Mass distribution of the concept machine



Fig. 19 Rotor Campbell diagram

Rotor dynamics is analyzed using a commercial structural FE package (Ansys). The $1^{\text {st }}$ and $2^{\text {nd }}$ modes shape and rotor dynamic Campbell diagram are shown in Fig. 19. The $1^{\text {st }}$ mode of the rotor occurs at a frequency of $134.4 \mathrm{~Hz}$ which is well above the 3,000 rpm operating speed of machine of $50 \mathrm{~Hz}$. With a bearing stiffness of $1 \times 10^{8} \mathrm{~N} / \mathrm{m}$ at both ends of the rotor shaft, the first critical speed is over $6,000 \mathrm{rpm}$ and well above the machine operating speed of $3,000 \mathrm{rpm}$. The machine is thus stable at its maximum operating speed.

\section{Conclusion}

A detailed description of design procedure of high power density electric motor, which is cooled by water glycol commonly used for cooling of power electronics on aircraft, was presented in the paper. The procedure includes an initial tradeoff study for the machine topologies with concentrated and distributed winding configuration. Analytical electromagnetic modelling as well as mechanical and thermal simulation had been used for optimization at this stage to down select the best machine topology from a broad range of configurations. The 15 pole pairs -36 slots fractional slot machine exposed the power density up to $4.8 \mathrm{~kW} / \mathrm{kg}$ and was selected for further optimization by using FEA.

Since the designed machine has a relatively high fundamental frequency the AC copper loss becomes significant. The FEA was performed for a standard round wire and litz wire to estimate the AC to DC copper loss ratio. It was shown that for the round wire with $1 \mathrm{~mm}$ strand diameter the AC to DC loss ratio is 4.64 at $750 \mathrm{~Hz}$ while for litz wire with the same strand diameter it can be reduced to 1.16 . For the real application the litz wire with $0.2 \mathrm{~mm}$ strand diameter was selected since it is more flexible and allows easier coil shaping. 
The results of FE optimization were also presented in the paper: the power density of the final design is about 5 $\mathrm{kW} / \mathrm{kg}$ with a power factor 0.73 and the efficiency of $97 \%$. Finally the mechanical design with the motor overview, diagram of passive-active mass distribution and the rotor dynamics diagram was given in the appropriate section.

\section{References}

[1] S. Bozhko, T. Yang, J.-M. Le Peuvedic, P. Arumugam,, M. Degano,, A. La Rocca, M. Rashed, W. Fernando, C. Ian Hill, C. Eastwick, S. Pickering, C. Gerada and P. Wheeler, "Development of Aircraft Electric StarterGenerator System Based on Active Rectification Technology," IEEE TRANSACTIONS ON TRANSPORTATION ELECTRIFICATION, vol. 4, no. 4, 2018.

[2] M. Farshadnia, M. Ali Masood Cheema, A. Pouramin, R. Dutta and J. E. Fletcher, "Design of Optimal Winding Configurations for Symmetrical Multiphase Concentrated-Wound Surface-Mount PMSMs to Achieve Maximum Torque Density Under Current Harmonic Injection," IEEE TRANSACTIONS ON INDUSTRIAL ELECTRONICS, vol. 65 , no. $2,2018$.

[3] D. Golovanov, D. Gerada, G. Vakil, Z. Xu, M. Degano and C. Gerada, "The Influence of Stator Material on the Power Density and Iron Loss of a High-Performace Starter-Generator for More Electric Aircraf," in 21st International Conference on Electrical Machines and Systems (ICEMS), Jeju, Korea, 2018.

[4] N. Korn, T. Vaimann, A. Kallaste and A. Belahcen, "Comparative study of slow-speed slotless synchronous generator using SmCo and $\mathrm{NdFeB}$ permanent magnets," in Electric Power Quality and Supply Reliability Conference (PQ), Rakvere, Estonia, 2014.

[5] S. Sjökvist and S. Eriksson, "Experimental Verification of a Simulation Model for Partial Demagnetization of Permanent Magnets," IEEE TRANSACTIONS ON MAGNETICS, vol. 50, no. 12, 2014.

[6] J. F. Liu and M. H. Walmer, "Thermal Stability and Performance Data for SmCo 2:17 High-Temperature Magnets on PPM Focusing Structures," IEEE TRANSACTIONS ON ELECTRON DEVICES, vol. 52, no. 5, 2005. 